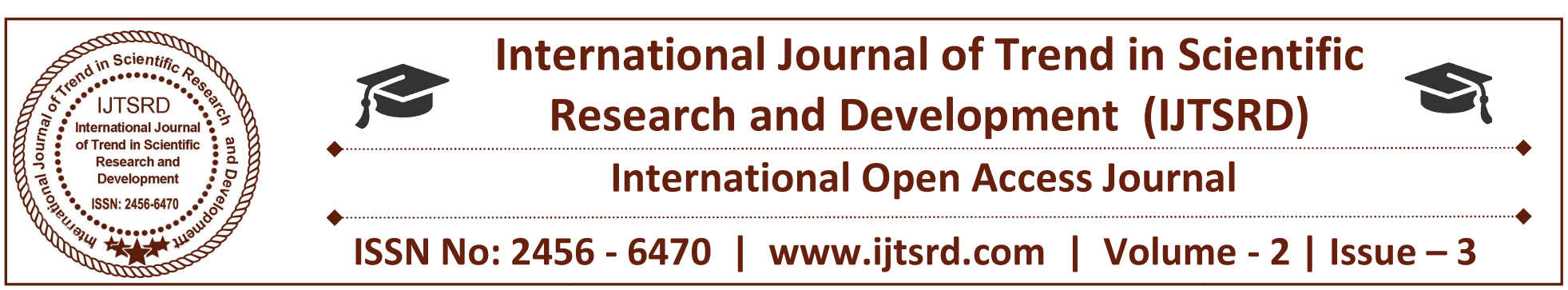

\title{
Assessing the Monthly Variation of Reference Evapotranspiration of Nsukka, Enugu State, Nigeria
}

\author{
Oyibo Muazu', Abdullahi Ayegba ${ }^{2}$ \\ ${ }^{1}$ Radio Astronomy Division, Centre for Basic Space Science, Nsukka, Nigeria \\ ${ }^{2}$ Department of Engineering and Space Systems, National Space Research and Development Agency \\ (NASRDA), Abuja, and Mathson Research Centre- A division of Mathson Group of Schools, Nigeria
}

\section{ABSTRACT}

The application of suitable water quantity to the crops in irrigation farming is very important for effective crop yields as less or more than the required quantity of water when applied will affect the crop output negatively. The objective of this work was to determine the monthly reference Evapotranspiration of Nsukka, Enugu state of Nigeria, as well as how its variation is affected by temperature change. This work made use of Hargreaves-Samani model of evapotranspiration prediction, using the data of minimum and maximum temperature obtained from NASA's earthdata database. It was shown from the results that highest evapotranspirationoccured in February, and lowest occurred in July. It was further observed that reference Evapotranspiration of the study area has a positive correlation coefficient of 0.9927 with the maximum temperature and a negative correlation coefficient of -0.1879 with the minimum temperature. Conclusively, it was stated that reference evapotranspiration was higher in the study area in dry season than in rainy season, and that it was directly proportional to the maximum temperature and inversely to the minimum temperature.

Keywords: Atmosphere, Evapotranspiration, Harmattan, Irrigation farming, Temperature

\subsection{INTRODUCTION}

Evaporation deals with the movement of water to the air from sources such as soil, water bodies and canopy interception, while transpiration deals with the movement of water within a plant as well as loss of water in a form of vapour through the stomata in the leaves (Gujahar\&Ayegba, 2017). Thus, Evapotranspiration is the combination of evaporation and transpiration which means the process movement or giving off of water vapour from the soil, water bodies as well as plants into the air or atmosphere.

Reference Evapotranspiration (ETo) is the evapotranspiration rate of short green crops (grass), completely shading the ground, of uniform height and with adequate water status in the soil profile. In order words, it is mainly concerned with crops rather than other tall plants in an area as regards how water is given off by them into the atmosphere at a particular time.

The advantage of calculating reference evapotranspiration of an area is that it is used to estimate the actual Evapotranspiration (ET), and which is calculated from the product of crop coefficient $(\mathrm{kc})$ and the reference evapotranspiration (ETo). Reference evapotranspiration (ETo) is the same for all crops but actual evapotranspiration varies since it depends on the crop coefficient which in turn depends on the specified crop as well as its stage of growth (Jalal, 2014)

Reference evapotranspiration (ETo), according to (Allen et al. 1998), is an important parameter for agro-meteorological for the studies of climate and hydrology, as well as for irrigation planning and management. Thus, estimating the reference evapotranspiration of a location such Nsukka, Enugu 
state as in the case of this work will help in climate, hydrology as well as irrigation planning.

Also, according to (Zohrab, 1996), reference Crop Evapotranspiration (ETo) is an important element in hydrological studies. ETo is important in agricultural and urban planning, irrigation scheduling, studying of regional water balance and agro-climatological zoning.

The temperature based model is one of the most widely used models for the estimation of evapotranspiration (Mohammed, 2015). Some of these models are Hargreave-Samani model, BlaneyCriddle model, Schendel model and Thorntwaite model, this work made use of Hargreave-Samani.

Although, some similar works have been done by some scientists in some parts of the country, this work focuses on Nsukka, a local government in Enugu state, south-east Nigeria.

\subsection{LITERATURE REVIEW}

Some of the works reviewed in the course of this study are

a. A Study Of Reference Evapotranspiration of Abuja, Nigeria by Gujahar and Ayegba, 2017. The work made use of data of maximum and minimum temperature for December and June 2015 and December 2016 obtained from weather online limited database. The result showed that the daily reference evapotranspiration of the study area was higher in dry season (December) than in rainy season (June) due to higher solar radiation in dry season.

b. Evaluation of Evapotranspiration using FAO Penman-Monteith Method in Kano Nigeria by Isikwueet al.,2014. Their work evaluated the reference evapotranspiration, ETo for Kano using the FAO Penman-Monteith Method, and the data (1977-2010) used was obtained from International Institute for Tropical Agriculture, Ibadan. It was observed by them that the highest reference evapotranspiration $(125.08 \mathrm{~mm} /$ day $)$ occurred in February and the lowest $(60.406 \mathrm{~mm} /$ day $)$ occurred in August. The observation was attributed to high air humidity and presence of cloud in August and dryness of weather in February.

c. Seasonal evapotranspiration signatures under a changing landscape and ecosystem management in Nigeria: Implications for agriculture and food security by Chineke et al., 2011. The work looked at seasonal and regional trends of evapotranspiration for 36 state capitals of Nigeria and the federal capital, Abuja using data obtained from the International Water Management Institute (IWMI) for the period 1961-1990. It was observed in their work that monthly mean evapotranspiration ranged from $2.68 \mathrm{~mm}$ in the month of August at Port-Harcourt in the coastal part of the country to $9.08 \mathrm{~mm}$ for the month of March at Sokoto in the northern part of the country.

d. CropEvapotranspiration- Guidelines for computing crop water requirements- FAO Irrigation and Drainage Paper 56 by Richard et al., 1998.

\subsection{MATERIALS AND METHOD}

\section{Materials}

The data used in this work is a secondary data of average monthly maximum and minimum temperature (July1, 1983 - June 30, 2005) obtained from earthdata.nasa.gov. Other material used is Microsoft excel software package.

II. Method: The work makes use of HargreavesSamani model of evapotranspiration prediction. Hargreaves-Samani model is the model which is used to estimate reference evapotranspiration of an area if maximum and minimum temperatures are the only available data. Microsoft excel worksheet was used for the mathematical computations to obtain the necessary parameters, and plotting of graphs.

The Hargreaves-Samani reference evapotranspirationmodel is given (Hargreaves and Samani, 1985) as:

$E T_{O}=0.0135(T+17.78) R_{s}\left(\frac{238.8}{595.5+0.55 T}\right)$

Where $T$ is the mean daily temperature in ${ }^{0} \mathrm{c}, R_{S}$ is the global solar radiation in $\mathrm{MJ} / \mathrm{m}^{2}$ day, and $E T_{o}$ is the reference evapotranspiration in $\mathrm{mm} /$ day.

\section{Procedure}

i. Solar radiation declination: Solar radiation declination is defined as the angle made between a ray of the sun, when extended to the centre of the earth and the equatorial plane. The solar radiation 
declination is represented mathematically (Iqbal, 1983; Zekai, 2008) as;

$$
\delta=0.409 \operatorname{Sin}\left(\frac{2 \pi}{365} J-1.39\right)_{\text {--------- } 2}
$$

where $\mathrm{J}$ is the number of the day in the year between 1 ( 1 January) and 365 or 366 (31 December) and $\delta$ is solar radiation declination in radian.

ii. Inverse relative distance Earth-sun: Inverse relative distance Earth-sun is the inverse distance of the sun relative to the earth at a location. It is represented (Iqbal, 1983; Zekai, 2008) as;

$$
d_{r}=1+0.033 \operatorname{Cos}\left(\frac{2 \pi J}{365}\right)
$$

iii. Sunset angle: Sunset angle is defined as the angle of the daily disappearance of the sun below the horizon due to the rotation of the earth. Sunset time is the time in which the trailing edge of the sun's disk disappears below the horizon. It is determined using the formula given (Iqbal, 1983; Zekai, 2008) as:

$$
\omega_{s}=\operatorname{Cos}^{-1}(-\tan (\varphi) \tan (\delta))
$$

where $\omega_{s}$ is sunset angle in radian, $\delta$ is the solar radiation declination in radian, and $\varphi$ is latitude angle of the location in radian.

iv. Extraterrestrial solar radiation: Extraterrestrial solar radiation is the intensity or power of the sun at the top of the earth's surface. The extraterrestrial radiation is calculated using the formula given (Iqbal, 1983; Zekai, 2008) as:

$$
R_{a}=\frac{24(60)}{\Pi} G_{s c} d_{r}\left[w_{s} \operatorname{Sin}(\varphi) \operatorname{Sin}(\delta)+\operatorname{Cos}(\varphi) \operatorname{Sin}\left(w_{s}\right)\right]
$$

where $R_{a}$ is extraterrestrial radiation, $d_{r}$ is the inverse relative earth-sun distance, $\varphi_{\text {is the latitude angle of }}$ the study area, $w_{s}$ is the sunset angle, and Gsc is solar constant $=0.0820 \mathrm{MJ} \mathrm{m}^{-2} \mathrm{~min}^{-1}$ or $1367 \mathrm{wm}^{-2}$.

v. Global Solar Radiation: Global solar radiation is the total amount of solar energy received by earth's surface. It is the sum of the direct, diffuse and reflected solar radiations. It is found using the formula given (Hargreaves and Samani, 1985) as:
$R_{s}=K_{R S}\left(\sqrt{T_{\max }-T_{\min }}\right) R_{a}$ 6

Where $T_{\max }$ is the maximum temperature, $T_{\min }$ is minimum temperature, $R_{a}$ is the extraterrestrial solar radiation of the area and $\mathrm{K}_{\mathrm{Rs}}$ is adjustment coefficient. For 'interior' locations, where land mass dominates and air masses are not strongly influenced by a large water body, $K_{R s}$ is approximately 0.16 and for 'coastal' locations, situated on the coast of a large land mass and where air masses are influenced by a nearby water body, $\mathrm{K}_{\mathrm{Rs}}$ is approximately 0.19 (Hargreaves and Samani, 1985). $K_{R s}$ is 0.16 in this work.

vi. Mean temperature: Mean temperature is obtained from the average of the monthly maximum and minimum temperatures. The mean temperature is calculated using the equation given as;

$$
T=\frac{T_{\min }+T_{\max }}{2}
$$

vii. Calculation of reference evapotranspiration: Evapotranspiration is the sum of the evaporation and plant transpiration from the earth's land and ocean surface to the atmosphere. Reference evapotranspiration is calculated using the formula given (Hargreaves and Samani, 1985) as:

$$
E T_{O}=0.0135(T+17.78) R_{s}\left(\frac{238.8}{595.5+0.55 T}\right)
$$

where $R_{S}$ is the global solar radiation in $\mathrm{MJ} / \mathrm{m}^{2}$ day, $T$ is the mean daily temperature in ${ }^{0} \mathrm{c}$, and $E T_{o}$ is the reference evapotranspiration in $\mathrm{mm} /$ day.

\subsection{RESULTS AND DISCUSSIONS}

Table 1.0 shows the average reference evapotranspiration, maximum and minimum temperatures of the study area. The average reference evapotranspiration was calculated using the data of maximum and minimum temperatures. The table shows that the average reference evapotranspiration varied throughout the year with the highest evapotransiration occurring in February and the lowest in July. The maximum reference evapotranspiration was $5.72 \mathrm{~mm} /$ day while the minimum reference evapotranspiration $3.61 \mathrm{~mm} /$ day. This means that the maximum amount of the water vapour that will be given off from the soil and the plants in the study area is $5.72 \mathrm{~mm}$ and this will take place in the month of February. 
International Journal of Trend in Scientific Research and Development (IJTSRD) ISSN: 2456-6470

Table 1.0: Average Reference Evapotranspiration, Maximum and minimum temperatures

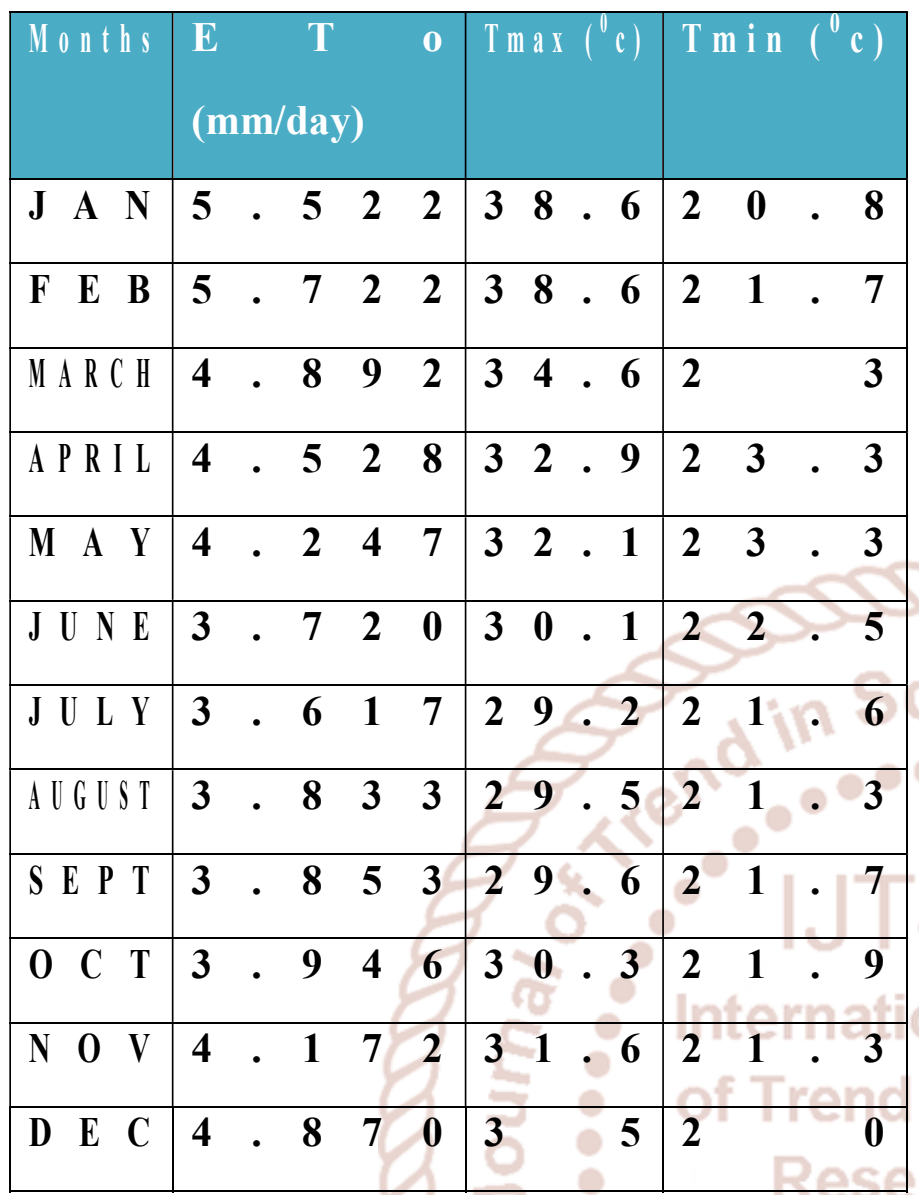

The trend of the variation of the reference evapotranspiration is such that it increased from January to February which was the peak, and then started decreasing slowly until the month of July where the lowest level was reached. The reference evapotranspiration then started rising until it reaches December before another decrease in January (Figures 1.0 and 2.0). As stated, there was a decrease in the value of reference evapotranspiration between December and January, this might be as a result of harmattan which will be charaterised with moist atmosphere thereby reducing the amount of water vapour given off from the earth's surface as well as by plants.

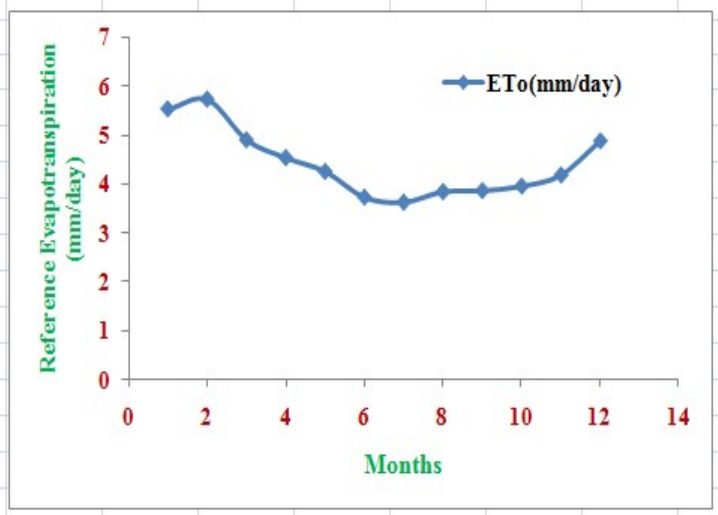

Fig. 1.0: Average Reference Evapotranspiration graphical representation

Also, there was an increase from January to February which might be as a result of break in harmattan or its total termination paving way for rain or more humid atmosphere from March . The least evapotraspiration recorded in July was as a result of heavy rainfall during that period. After this month, the gradual reduction in the amount of rainfall experienced in the placed led to the continuous but slow increase in the level of evapotranspiration till the end of the year.

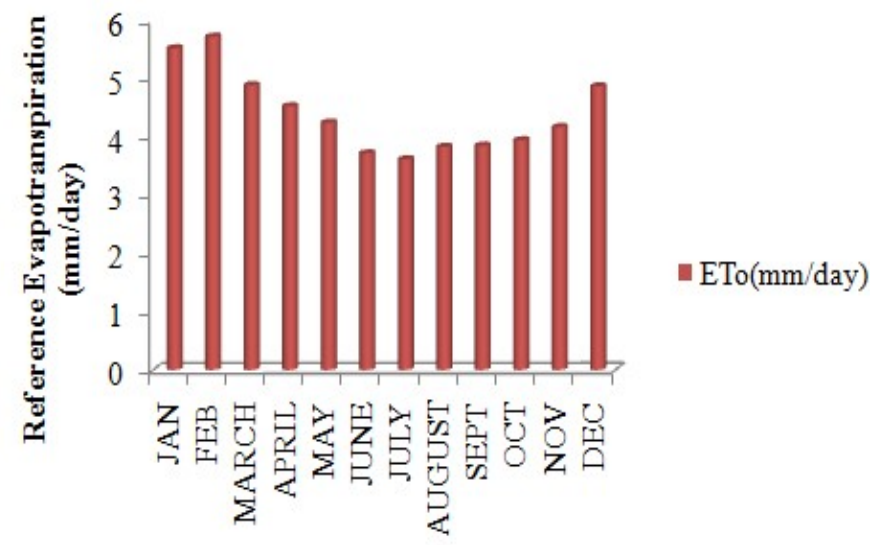

Fig. 2.0: Average Reference Evapotranspiration bar chart representation

The implication is that irrigation farmers would have to study this trend for effective application of water to their crops since Nsukka is well know for the growing of tomatoes, perpe, potatoes, coco yam, maize and many other crops during dry season with some mostly grown with irrigation. For instance, perpe is a biannual crop, that is; it spends two years life span before it dies. This is possible when the temperature is not much, and when there is sufficient water in the soil to sustain it during dry season. In this study area where the evapotranspiration is somewhat high, 
especially fron December to March, there is need for artifcial or additional water to be applied to crops such as perpe in order to sustain them during this period. In addition, crops like tomatoes will continue to produce if adequate water is apllied, and at the right time. In other words, the amount of water applied to the farmland in December will be less than that which will be applied in January, and the one that will be applied to the farmland in January will be less than that is February (Table 1.0). This work will be of immense benefit to the farmers in this study area.

Figure 3.0 shows the graphical relationship between the averagereference evapotranspiration, maximum and minimum temperatures. It can be observed from the figure that average reference evapotranspiration is mostly related to the maximum temperature $\left(\mathrm{T}_{\max }\right)$ when the trend of the changes in both are compared even though that change in the average reference evapotranspiration is not as noticeable as in maximumtemperature. From the beginning of the year, both of them were increasing, then decreasing and again increasing almost at equal points.

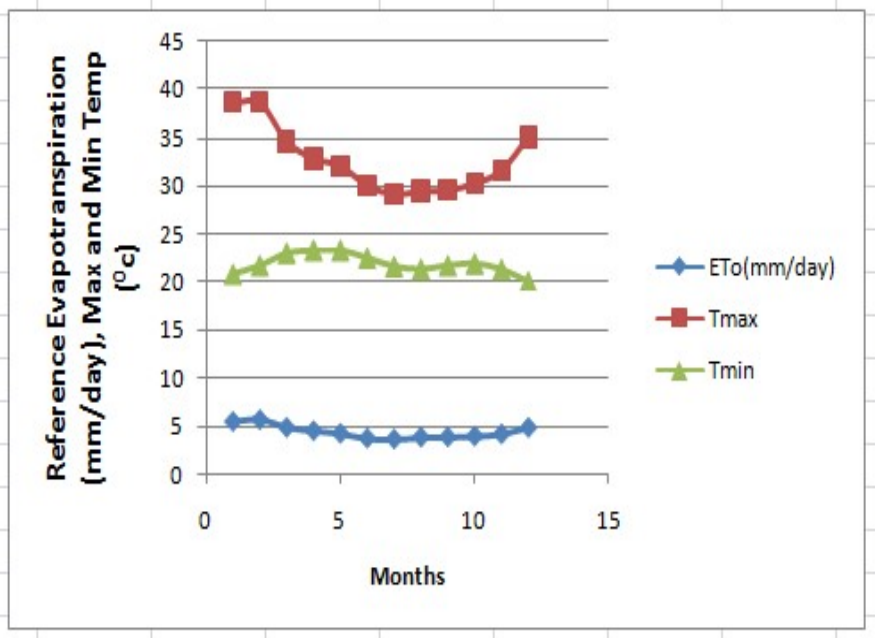

\section{Fig 3.0: Monthly Average Reference Evapotranspiration, maximum and minimum temperatures graphical representation}

With further comparison, the correlation analysis of average reference evapotranspiration, maximum and minimum temperatures were carried out using Pearson correlation method in excel worksheet. It was discovered that the correlation coefficient between the average reference evapotranspirationand maximum temperature was 0.9928 , while the coefficient between the minimum temperature was 0.188.Therefore, both the maximum and minimum temperatures have effect on the reference evapotranspiration of the study area but maximum temperature has more effects when compared to that of minimum temperature because maximum temperature has $99.28 \%$ relationship with the reference evapotranspiration while minimum temperature has $18.79 \%$ relationship with the reference evapotranspiration. Furthermore, even though it has been observed that both temperatures have effects on reference evapotranspiration, the positive correlation coefficient $(0.9928)$ between the maximum temperature and reference evapotranspiration shows that reference evapotranspiration increases with increase in maximum temperature and vice versa. Also, the negative correlation coefficient $(-0.1879)$ between the minimum temperature and reference evapotranspiration shows that reference evapotranspiration increases with decrease in minimum temperature and vice versa.

\subsection{CONCLUSION}

The monthly average reference evapotranspiration of the Nsukka (Lat $6.84^{\circ} \mathrm{N}$, Long $7.37^{0} \mathrm{E}$ ), South-East Nigeria has been determined using HargreavesSamani method. The study made use of data of minimum and maximum temperature of NASA's earthdata database for twenty two years (July1, 1983 - June 30, 2005). From the result, it was observed that higher average reference evapotranspirationwas experienced in the study area from December to March with February having the peak level while July has the least level of evapotranspiartion. It can be concluded from the result that reference evapotranspiration is higher in dry season and lower in rainy season because less water is given off into the atmosphere. It can also be concluded that although reference evapotranspiration is affected by both maximum and minimum temperature, maximum temperature (correlation coefficient of $99.28 \%$ ) has more effect on it than minimum temperature (correlation coefficient of $18.79 \%$ ).

Finally, due to positive and negative correlation coefficient between reference evapotranspiration in relation to the maximum and minimum temperature respectively, it will be concluded that reference evapotranspiration of the study area is directly proportional to the maximum temperature and inversely to the minimum temperature. 


\subsection{RECOMMENDATIONS}

It is recommended that other models for determining reference evapotranspiration of an area be used for the same area since this work made use of HargreavesSamani method.

\section{REFERENCES}

1. Allen G R. Pereira S L, Raes D, and Smith, M. (1998): Crop evapotranspiration: Guidelines for computing crop water requirements. Food and Agricultural Organization of the United Nations (FAO) Rome.Publication No. 56.

2. Chineke T. C, Idinoba M. E and Ajayi O. C (2011): Seasonal evapotranspiration signatures under a changing landscape and ecosystem management in Nigeria: Implications for agriculture and food security, American. J. Sci. Ind. Res., Vol 2(2), Pp 191-204.

3. Fernandez J. E., Green S. R., Caspari H. W., DiazEspejo A., Cuevas M. V. (2008). The use of sap flow measurements for scheduling irrigation in Oolives apple and Asian pears trees and in grape vines.

4. Gordon Bonan (2014): Modeling terrestrial ecosystems: Biogeophysics\& / canopy processes,National Center for Atmospheric Research Boulder, Colorado, USA. Pg 1-35.

5. Gujahar R. D. R, and AbdullahiAyegba (2017). A study of Reference Evapotranspirationof Abuja, Nigeria. International Journal for Research \&Development in technology. (8)2. Pp 72-78

6. Hargreaves, G. and Samani, Z. (1982). Estimating potential evapotranspiration.Journal of Irrigation and Drainage Engineering.

7. Iqbal M. (1983). An introduction to solar radiation, first ed. Academic press, New York.

8. Isikwue, C. Bernadette, Audu, O. Moses, Isikwue, O. Martin (2014). Evaluation of Evapotranspiration using FAO Penman-Monteith Method in Kano Nigeria. International Journal of Science and Technology

9. JalalShiri (2014): "How to calculate the actual evapotranspiration from potential evapotranspiration?"

www.researchgate.net/post/How_to_calculate_act ual_eva....

10. Mohammad Valipour (2015): “Temperature analysis of reference evapotranspiration models", Wiley online library, Meteorol. Appl. 22, Pp 385394

11. Ugwu, A. I. and Ugwuanyi, J. U. (2011). Performance assessment of Hargreaves model in estimating solar radiation in Abuja using minimum climatological data, International Journal of the Physical Sciences.

12. Richard G. ALLEN, Luis S. PEREIRA, Dirk RAES, Martin SMITH (1998). Crop Evapotranspiration- Guidelines for computing crop water requirements- FAO Irrigation and Drainage Paper 56. Available at https//www.researchgate.net/publication/2357041 97

13. ZohrabSamani (1996) Estimating Solar Radiation and Evapotranspiration Using Minimum Climatological Data. New Mexico State University

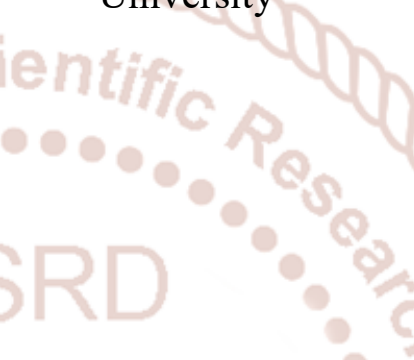
n 